\title{
Experiência Estética para uma Aprendizagem Inventiva: notas sobre a acessibilidade de pessoas cegas a museus*
}

\section{Aesthetic Experience for Inventive Learning: notes on the accessibility of blind people to museums}

\begin{abstract}
Resumo:
O objetivo deste texto é discutir a natureza da experiência estética e seu papel na cognição inventiva, examinando sua relação com a atenção e seus efeitos sobre a aprendizagem. Na primeira parte analisa o conceito de experiência estética em John Dewey (1950/1980), questiona a separação entre o que habitualmente chamamos de percepção estética e de prática artística e aponta que ambas são capazes de acionar processos de aprendizagem inventiva (Kastrup, 2007a). É também examinada a noção de aprendizagem por cultivo (DEPRAZ, VARELA; VERMERSCH, 2003). O texto traz ainda alguns resultados de uma pesquisa de campo realizada na oficina de cerâmica do Instituto Benjamin Constant, no Rio de Janeiro, que teve como objetivo investigar o funcionamento da atenção durante processos de criação em pessoas com deficiência visual. Estudando pessoas cegas e com baixa visão na prática com a cerâmica, a pesquisa verifica os efeitos de transformação de si e de produção de subjetividade que as práticas artísticas comportam. Por este caminho, o texto traz elementos para a discussão sobre a questão da acessibilidade para pessoas com deficiência visual em museus.

Palavras-chave: Experiência estética. Aprendizagem inventiva. Deficiência Visual - Acessibilidade - Museus
\end{abstract}

\section{Abstract:}

The objective of this text is to discuss the nature of the aesthetic experience and its role on inventive cognition, studying its relationship with the attention and its effects on learning. In the first part, this text analyses the concept of aesthetic experience in John Dewey (1950/1980). It questions the separation between what we usually call aesthetic perception and artistic practice, and he points out that both are able to set off processes of inventive learning (Kastrup, $2007 a$ ). It also analyses the notion of learning by cultivation (DEPRAZ, VARELA; VERMERSCH, 2003). The text puts forward some results from a field research carried out in a pottery workshop at the Benjamin Constant Institute, in Rio de Janeiro. Its objective was to investigate the functioning of the attention during processes of creation in people with visual disability. Studying blind people and people with low vision practicing pottery, the research verifies the effects of the transformation of oneself and the production of subjectivity that the artistic practices include. In this way, the text offers elements on the discussion about accessibility for people with vision disability to the museums.

Keywords: Aesthetic experience. Inventive learning. Visual disability - Accessibility - Museums.
KASTRUP, Virginia. Experiência Estética Para uma Aprendizagem Inventiva: notas sobre a acessibilidade de pessoas cegas a museus. Informática na Educação: teoria \& prática, Porto Alegre, v. 13, n. 2, p. 38-45, jul./dez. 2010.
Virgínia Kastrup

Universidade Federal do Rio de janeiro

\section{Introdução}

N uma longa entrevista concedida a Claire Parnet, o filósofo Gilles Deleuze dá uma curiosa resposta quando convocado a discorrer sobre a palavra cultura. A entrevistadora começa com uma provocação: "Você diz não ser culto. Diz que só lê, vê filmes ou olha as coisas para um saber preciso: aquele que você precisa para um trabalho definido, preciso, que está fazendo. Mas, ao mesmo tempo, você vai todos os sábados a uma exposição, a um filme". Deleuze responde que não acredita na cultura em si, mas nos encontros, não só com pessoas mas, sobretudo, com coisas. Busca encontros. "Quando vou sábado e domingo ao cinema, etc. não estou certo de ter um encontro, mas parto à espreita [...]" (DELEUZE, 1997). O que o move quando vai a uma exposição ou a um museu é a expectativa de ter encontros. Deleuze não procura estes espaços para ter cultura, e sim para se cultivar. Sua relação com a cultura e a arte não é para acumular saber, mas para cultivar uma forma especial de atenção - uma atenção à espreita - que ele considera fundamental para acionar seu pro-

\footnotetext{
* A base deste texto foi uma conferência apresentada no Seminário Internacional Ciência e Museologia: Universo Imaginário, organizado pelo MUSAETEC Grupo de pesquisa e estudos em Museologia, Arte-Estética na Tecnologia, Educação e Ciência, realizado em Belo Horizonte em 2007. Uma versão preliminar foi publicada nos Anais do evento.
} 
cesso de criação de conceitos filosóficos. A colocação de Deleuze indica que quando vamos a um museu - seja ele de artes ou de ciências - podemos ir em busca de encontros, de experiências e de aprendizagem, e não de informação e de um saber pronto para ser absorvido e consumido. Em outras palavras, podemos ir ao encontro de algo que nos surpreenda, que nos provoque estranhamento, que nos force a pensar, enfim, que desencadeie em nós mesmos processos de criação, ou do que eu chamo de aprendizagem inventiva (KASTRUP, 2007a, KASTRUP; TEDESCO; PASSOS, 2008). Enfim, podemos dizer que a ida a um museu pode ser uma experiência estética.

O objetivo deste texto é discutir a natureza da experiência estética e seu papel na cognição inventiva, examinando sua relação com a atenção e seus efeitos sobre a aprendizagem. Na primeira parte vou desenvolver esta idéia através da análise do conceito de experiência estética em John Dewey (1980). A chave do uso que farei das idéias de Dewey consiste em seu questionamento da separação entre o que chamamos de percepção estética e que chamamos de prática artística. Dewey defende que embora a palavra estético se refira primordialmente ao ato de percepção e apreciação e a palavra artístico ao ato de produção, o conceito de experiência estética revela a profunda conexão entre o estético e o artístico, entre a percepção e a criação. Nesta direção, tomarei tanto a percepção estética como a prática artística em seu papel de acionar processos de aprendizagem inventiva. Buscarei apresentar esta noção juntamente com aquela de aprendizagem por cultivo, desenvolvida no campo das ciências cognitivas contemporâneas por Francisco Varela, Natalie Depraz e Pierre Vermersch. Na segunda parte vou trazer alguns resultados de uma pesquisa de campo que realizo na oficina de cerâmica do Instituto Benjamin Constant, no Rio de Janeiro. A pesquisa tem como objetivo investigar 0 funcionamento da atenção durante processos de criação em pessoas com deficiência visual. Estudando pessoas cegas e com baixa visão na prática com a cerâmica, tenho verificado de perto os efeitos de transformação de si e de produção de subjetividade que as práticas artísticas comportam. Por este caminho vou trazer alguns elementos para a discussão sobre a questão da acessibilidade para pessoas com deficiência visual em museus.

\section{Em Torno do Conceito de Experiência Estética}

Qual a especificidade da experiência estética em relação à experiência em geral? Para Dewey (1980) a experiência estética não se define pelo objeto ao qual ela corresponde - uma obra de arte, por exemplo - nem por algum traço especial, como a beleza, que se introduziria na experiência comum. Segundo Dewey qualquer teoria estética deve tomar como base que a experiência estética é o desenvolvimento clarificado e intensificado da experiência em geral. Ela existe frente à arte, mas também emerge na vida cotidiana. Ela se define, entretanto, como uma experiência especial, que faz com que a vida não se apresente como uma corrente homogênea e uniforme de fatos banais. Ela surge entrecortada por experiências marcantes. Um jantar, uma música, um encontro, uma tempestade ou uma viagem podem ser experiências desta natureza. Ao nos referirmos a ela dizemos: "Foi uma experiência!" (DEWEY, 1980, p. 90).

Podemos definir a experiência estética por algumas qualidades. Conforme dito acima, a primeira é tratar-se sempre de uma experiência marcante, que não se dissipa e que não é facilmente esquecida. A segunda é ser uma experiência que possui uma unidade, onde as partes constituintes são reunidas sem emendas ou vazios. Ainda que composta por partes sucessivas, estas são reunidas numa síntese. A terceira é que tal unidade inclui de modo indistinto as dimensões emocional, prática e intelectual, que só a posteriori podem ser separadas. A dimensão emocional responde pelo caráter de totalidade da experiência, sendo própria da dimensão prática a conexão do corpo com o mundo a sua volta e da dimensão intelectual dar finalmente seu significado. A emoção é uma qualidade da experiência, ou seja, a experiência estética é emocional. Mas não existem nela coisas separadas chamadas emoções. De todo modo, emoções significativas são relativas a objetos ou situações; são de alguém, mas não têm um caráter totalmente privado. A experiência estética se caracteriza ainda por surgir como a consumação de um movimento, a culminância de um processo. Este aspecto dá a ela a qualidade de uma experiência concluída, como quando uma pedra pára depois de rolar 
colina abaixo. Ela pode durar alguns minutos, como quando lemos uma poesia, ou um longo período como quando fazemos uma viagem. De todo modo, dizemos como Dewey (1980, p. 90) que: "Foi uma experiência!" Uma outra característica é a incorporação vital, que vem através das sensações de prazer ou dor que a acompanham. De todo modo, a experiência estética não é aquela meramente divertida ou que gera entretenimento, mas sim aquela que é marcada por sensações intensas. Neste sentido, Dewey (1980) afirma que os inimigos da estética não são nem a vida prática nem a vida intelectual, mas a lassidão e indefinição dos fins, bem como a monotonia e a convenção, que podem destituir de caráter estético tanto a vida prática quanto a vida intelectual. As qualidades acima enumeradas remetem umas às outras. Assim, o caráter sintético e o caráter de conclusão de um movimento são indissociáveis, e se explicam pela existência da dimensão emocional. Por outro lado, a indistinção entre as dimensões emocional, prática e intelectual faz dela uma experiência propícia à incorporação vital.

Dewey (1980) fala de experiência de caráter estético e não de experiência estética em sentido estrito. A experiência estética é encontrada na vida, sempre que ela deixa de ser uma banalidade. A arte produz de modo especial experiências estéticas e é por esta razão que falamos de arte quando queremos tratar de estética. $O$ importante do conceito de Dewey é que ele não coloca a arte num campo de transcendência, nem a experiência com a arte num âmbito restrito a seres supostamente especiais - aqueles que possuem cultura, no caso dos apreciadores - ou genialidade, no caso dos artistas. Dewey (1980) aproxima a estética da vida, o que torna suas idéias bastante fecundas para entender o papel da arte em âmbitos muito diversos. Tenho verificado a potência da arte no contexto de trabalhos sociais e comunitários, da reforma psiquiátrica brasileira e dos processos de reabilitação das pessoas com deficiência visual. Em todos estes espaços a experiência estética surge acionando processos de produção de subjetividade e de transformação social. É o caso também da experiência estética em museus de artes e de ciências, como veremos adiante.

Ainda acompanhando a argumentação de Dewey (1980), constatamos que o vocabulário comum atribui à expressão prática artística uma característica ativa e à expressão percepção estética uma característica passiva. Mas Dewey aponta que a experiência estética é receptiva, sem ser propriamente passiva nem ativa. O fazer não se separa do sofrer, ou seja, do gosto. O artista, enquanto trabalha, incorpora a atitude de quem percebe. Por outro lado, a ação artística só se completa com a participação do expectador, daquele que percebe o obra em questão. Neste sentido, a experiência perceptiva é, ela própria, uma experiência criadora, completando o trabalho de produção (DEWEY, 1980).

A receptividade da experiência estética faz da percepção algo distinto do mero reconhecimento. $O$ reconhecimento é uma percepção interrompida, no sentido em que a experiência presente é rebatida sobre a experiência passada, fazendo com que o novo perca seu estatuto de novidade. Distinta do reconhecimento, a percepção estética é receptiva. Ela consiste em se deixar impregnar, em mergulhar com atenção, evitando uma interrupção precipitada. Aqui a posição de Dewey é próxima da de $\mathrm{H}$. Bergson, que distingue a percepção a serviço da vida prática, movida pelo interesse e colocada a serviço da ação, e a percepção estética, desinteressada e livre das limitações da vida utilitária (BERGSON, 2006a, 2006b). A posição da fenomenologia também vai na mesma direção. Na atualidade, no movimento denominado Pragmática Fenomenológica, Natalie Depraz, Francisco Varela e Pierre Vermersch $(2003,2006)$ têm buscado desenvolver o método de redução fenomenológica de Husserl, indicando o caminho de sua implementação através de práticas concretas. Os autores sublinham que para Husserl a experiência estética produz a suspensão de juízos e da atitude natural. Destacam ainda que algumas práticas são especialmente capazes de criar condições para a suspensão dos juízos e da atitude natural. A prática da meditação budista, a escrita de um texto, o estudo da filosofia e a sessão de psicanálise são algumas delas. Não se trata de uma lista fechada e outras possibilidades têm sido estudadas, envolvendo experiências artísticas em contextos individuais (CABRAL, 2006) e coletivos, como oficinas de leitura com crianças pobres (KASTRUP, 2002), rodas de poesia com empregadas domésticas (KASTRUP, 2003) e oficinas de cerâmica com deficientes visuais (KASTRUP, 2008). O que caracteriza tais práticas é a mo- 
bilização de uma atenção especial, que Deleuze chamou de à espreita e que eu descrevo como concentrada e, ao mesmo tempo, aberta (KASTRUP, 2004). É uma atenção diferente daquela mobilizada para a realização de uma tarefa específica ou para a solução de um problema definido. É uma atitude atencional de abertura para o encontro e para o acolhimento da novidade inesperada.

\section{Aprendizagem Inventiva e Cultivo da Atenção Numa Oficina com Cegos}

Tenho procurado pensar os processos de aprendizagem inventiva que têm lugar em oficinas de práticas artísticas. A partir da perspectiva da invenção, a aprendizagem não se resume a um processo de solução de problemas, mas inclui a invenção de problemas, a experiência de problematização (KASTRUP; TEDESCO; PASSOS, 2008). Também não equivale a um processo de adaptação a um mundo pré-existente, mas consiste na invenção do próprio mundo. A aprendizagem inventiva inclui a experiência de problematização, que se revela através do que Varela (1994) chamou de breakdowns, que constituem rupturas no fluxo cognitivo habitual. Podemos dizer que a experiência estética é uma experiência de breakdown, no sentido em que ela nos desloca e nos força a pensar. As oficinas procuram criar condições para o que Depraz, Varela e Vermersch (2006) denominam de aprendizagem por cultivo. Os autores afirmam: "Cantores não precisam criar seu aparato vocal, mas sim, sobre a base deste aparato, desenvolver um instrumento perito que os permite cantar (DEPRAZ; VARELA; VERMERSCH, 2006, p. 100). E continuam: "Pianistas não precisam construir mãos para tocar, mas levam anos e anos criando mãos de pianistas: fortes, destras, calibradas no espaço, com uma extraordinária precisão" (DEPRAZ; VARELA; VERMERSCH, 2006, p. 100). As mãos do pianista não se definem por seu aparato biológico, mas pela destreza, firmeza, precisão e perícia no movimento dos dedos. A capacidade de desenvolver movimentos tão finos e precisos existia como virtualidade, mas precisou ser cultivada através de uma prática repetida e por um treino disciplinado, para que então pudesse ser criada. O corpo biológico surge como esta reserva de virtualidade, o mesmo valendo para as qualidades da atenção. O que quero destacar aqui é que a noção de cultivo embaralha a lógica linear do aprendizado, constituindo uma superação da noção de aprendizagem como aquisição de informações.

Nesta direção, venho falando do cultivo da atenção à espreita, desta atenção concentrada e aberta à experiência de problematização. Note-se que habitualmente, quando se fala da relação entre aprendizagem e atenção, considera-se a atenção como condição do processo de aprendizagem. Entretanto, tenho procurado sublinhar a importância de colocar um outro problema, aquele do aprendizado da própria atenção que é suscitada pela experiência estética.

Ao iniciar um trabalho no campo da deficiência visual, a primeira coisa que aprendemos é que não existe o cego ou o deficiente visual. Há imensas diferenças entre cegueira congênita e adquirida, cegueira total e baixa visão, perda súbita e gradual da visão e entre os cegos que receberam cuidados, estimulação e educação apropriada e aqueles que não dispuseram de tais oportunidades. Aprendemos também que ver e não ver não constitui um problema meramente fisiológico (SACKS, 1995). Num mundo marcado pela hegemonia da visão, e na contemporaneidade pela forte dominação das imagens visuais, é bastante notável a produção social da deficiência (VYGOTSKI, 1997). Vivemos num mundo cujo paradigma é visuocêntrico e por isto muitas vezes a cegueira é descrita apenas em sua dimensão de falta, de déficit. No entanto, acompanhando o trabalho na oficina de cerâmica com pessoas que haviam perdido a visão - que apresentam problemas bem específicos e distintos dos cegos congênitos - foi possível constatar que existe nestas pessoas por certo deficiência, mas também uma grande potência para a reinvenção de suas vidas - e a arte desempenha aí um importante papel. A ceramista Clara Fonseca (2005), que coordena o trabalho da oficina de cerâmica do IBC, costuma dizer que se interessa sobretudo pelo que denomina de efeitos colaterais da cerâmica. Isto quer dizer que ao lado das peças que são produzidas, subjetividades são moldadas, existências são esculpidas, vidas são reinventadas. Há aí um claro papel da experiência estética na produção de subjetividades, na transformação de domínios cognitivos e no engendramento de novos territórios existenciais. 
O que parece importante ressaltar é que nossa observação na oficina de cerâmica tornou clara a importância de um processo de auto-criação para uma mudança da relação consigo, que por certo tem ocorrido com os participantes da oficina de cerâmica. Os trabalhos que falam sobre a auto-estima, tão em voga nos dias atuais, destacam a importância do outro, ou seja, das outras pessoas e daquilo que elas expressam e verbalizam, na constituição da chamada dimensão avaliativa do auto-conceito. Nas explicações correntes é sobretudo a relação com os outros que molda a relação consigo. Numa outra direção, argumentamos que o mais importante não é o que é dito pelo outro, nem o reforço da camada externa do self e suas marcas identificatórias. O mais importante é a experiência de criação e sua contra-face, a experiência de auto-criação, que potencializa o si mesmo virtual, concorrendo para o desprendimento da crosta identificatória que muitas vezes recobre a subjetividade de deficientes visuais (KASTRUP, 2006, 2008).

A oficina desempenha um importante papel na renovação do território existencial dessas pessoas. A aprendizagem inventiva, num de seus sentidos mais importantes, é invenção de mundo, através da ampliação de redes e de conexões. Neste processo, salvo em casos excepcionais, as pessoas não deixarão de ser cegas nem voltarão a ser videntes como eram antes. O desafio é reativar os links de pertencimento. Nesta direção, a oficina revelou-se um dispositivo potente. Acessar e ter ciência da virtualidade, para além da identidade de cego ou deficiente visual é, produzir o que, paradoxalmente, já estava lá. Acometidos de forma inesperada pela cegueira, é importante experimentar tais sensações e acionar outras forças. Na cerâmica, elas encontram, na ponta dos dedos, os recursos para sua própria reinvenção (KASTRUP, 2007b, 2008).

\section{Museu Como Oficina de Aprendizagem Inventiva}

No que diz respeito à acessibilidade dos cegos aos museus, parecem existir duas orientações ou políticas que vêm sendo seguidas. A primeira é uma política do acesso à informação e a outra é uma política do acesso à experiência, onde se destaca o papel da experiência es- tética. Embora a informação tenha seu papel na vida cotidiana, é sobretudo praticando a segunda dessas políticas que abrimos o caminho para os processos de aprendizagem inventiva. A primeira privilegia a transmissão de informações sobre as obras, sobre seus criadores e sobre seu contexto histórico. Para isto lança mão de dispositivos como maquetes, mapas táteis, gravações em áudio e recursos diversos em Braille (placas, folhetos, etc). Em se tratando de obras de arte, o mapa tátil dificilmente é capaz de produzir a percepção do que a arte tem de arte, pois ele se limita a representar uma forma. E o acesso á arte depende mais da percepção da dimensão expressiva da obra do que de sua dimensão representativa. É o campo de forças que deve ser apreendido, ou seja, a dinâmica da forma (ARNHEIM, 1989, DELEUZE, 1981, FERRAZ, 2010) Ocorrem muitas dificuldades, sobretudo envolvendo cegos congênitos, cujo sistema cognitivo é construído em bases totalmente distintas, o que faz com que seus métodos e seu sistema de representação sejam muito específicos. No caso de cegos tardios, a informação tátil ou auditiva pode não produzir qualquer experiência nova, limitando-se ao simples reconhecimento, à mera atualização de uma experiência passada ou de um saber prévio.

Uma orientação mais interessante é a política de acessibilidade voltada para a aprendizagem inventiva. Aqui o mais importante não é a informação, mas a experiência marcada pela emoção estética. A ênfase na informação corre o risco de produzir o que no campo da deficiência visual é conhecido como verbalismo, que é a utilização de palavras destituídas do substrato concreto da experiência. Por exemplo, alguns autores têm ressaltado que os métodos verbais que tentam fazer com que os cegos compreendam as cores ou o conteúdo de uma pintura se situam apenas no campo do enriquecimento dos conhecimentos e não naquele da experiência estética (HATWELL; STRERI; GENTAZ, 2000). A política da aprendizagem inventiva tem na experiência estética uma importante aliada, já que é ela que vai abrir a subjetividade para o acolhimento de sensações, afetos, forças, intensidades, surpresas, perturbações e enigmas que forçam a pensar. O aparente acesso direto dos cegos às esculturas poderia levar a crer que estas não colocam maiores problemas. No entanto, sabemos hoje em dia que não é bem assim. Os cegos 
têm uma percepção tátil especializada para os materiais - texturas, peso, temperatura - o que traz vantagens e desvantagens quando se trata de experiência estética. Um cego pode perfeitamente estranhar que o rosto, os cabelos e as roupas de uma pessoa tenham a mesma textura numa escultura. Evitemos, então, as conclusões fáceis e apressadas (CARIJó; ALMEIDA; KASTRUP, 2010). Sem falar de certas dificuldades apontadas pelos próprios cegos, há que se destacar as dificuldades e resistências dos colecionadores e conservadores de expor obras de seu patrimônio às mãos e dedos dos cegos (CANDLIN, 2004).

Muitas têm sido as soluções encontradas, como salas especiais contendo apenas reproduções de obras famosas e visitas guiadas especiais para portadores de deficiência visual. Muito tem sido feito, mas há ainda temos um longo caminho pela frente. $O$ importante é entender a especificidade da percepção das pessoas cegas e, neste sentido, a psicologia cognitiva tem uma importante contribuição. Por outro lado, é necessário ter clareza quanto aos objetivos da acessibilidade, que deve ir além da mera decisão na direção do politicamente correto. Por fim, a política de acessibilidade está sempre sintonizada com a política de ensino e aprendizagem do próprio museu, seja para pessoas com deficiência ou para o publico em geral. Se o que se visa não é apenas a transmissão de informação, o conceito de museu pode ser aproximado do próprio conceito de oficina. As oficinas são espaços de fazer junto e são propícias para compartilhar experiências. O museu pode se tornar um espaço onde experiências são compartilhadas, a atenção é cultivada e a aprendizagem inventiva tem lugar.

Na direção de aproximar o fazer e a apreciação para o cultivo da experiência estética, alguns autores têm indicado, por exemplo, que a prática da argila deveria preceder a experiência de apreciação de esculturas de cerâmica. Todavia, a aproximação do conceito de museu com o de oficina vai além de procedimentos desta natureza. Ela diz respeito à proposta educacional de fazer deste espaço um território propício à surpresa, à emoção, ao acolhimento do inesperado, ao despertar do pensamento e da crítica, ao acionamento de movimentos inventivos, tanto cognitivos quanto existenciais.

Fiona Candlin $(2003,2004)$ tem feito importantes pesquisas, dando voz aos deficien- tes visuais através da realização de entrevistas onde eles avaliam os programas de acessibilidade de alguns museus britânicos. Tem sido constantemente destacada a insuficiência de colocar o problema de forma dicotômica - videntes e deficientes. Os deficientes visuais formam um grupo bastante heterogêneo, com características fisiológicas, sociais, culturais e educacionais muito distintas. Suas razões para visitar um museu variam tanto quanto variam entre os videntes. Pessoas cegas podem ir ao museu porque apreciam um movimento artístico como o impressionismo, porque se interessam pela iconografia cristã, porque é um lugar para levar seus filhos ou para encontrar amigos, porque gostam da quietude do local, porque o café de lá é bom, para comprar objetos na lojinha ou para ver algo que é pertinente ao seu trabalho. Visitas guiadas são uma boa iniciativa, mas elas não devem se limitar a informações para iniciantes. Nesta medida, é importante evitar o equívoco que consiste em confundir uma deficiência sensorial específica com uma deficiência intelectual generalizada. Programas regulares com mediadores disponíveis em horário integral ou semi-integral são bem vindos, mas devem atender diferentes níveis e contemplar o desenvolvimento progressivo dos visitantes. Salas especiais para cegos são um dispositivo de inclusão bastante limitado. Afinal de contas, ir a um museu envolve um encontro com as obras, consigo mesmo e com as pessoas. A interação com os demais visitantes videntes têm sua importância, em muitos casos. Ao lado do fácil acesso a recursos em áudio e em Braille, foi destacada a necessidade de uma formação adequada de mediadores de maneira a facilitar o acesso de pessoas com necessidades especiais. É preciso que os mediadores tenham ciência de que o tato é um sentido mais lento, que requer tempo, pois funciona por partes sucessivas e não por apreensão simultânea, como é mais claramente o caso da visão (REVESZ, 1950, GIBSON, 1962, HATWELL; STRERI; GENTAZ, 2000). Além disto, os mediadores devem convidar os cegos ao toque estético, que requer a atenção concentrada e aberta (KASTRUP, 2004, 2010). A maneira de descrever uma obra também exige cuidado. Não basta um texto padronizado dito de modo automático e burocrático. O desafio é acionar, acompanhar e compartilhar uma experiência estética. Tudo isto tendo em vista que a proposta é menos 
de transmissão de informação e de acumulação de saber do que de cultivo da sensibilidade e de invenção de si e do mundo.

Enfim, há necessidade de todo um trabalho experimental e ao mesmo tempo investigativo para a inclusão de deficientes visuais, que pode ser ocasião para um questionamento da política educacional do próprio museu. Como conclui Fiona Candlin (2003) sem mudança institucional, os eventos educativos para cegos continuarão a ser um suplemento inadequado para uma estrutura museal que se mantém intacta.

\section{Referências}

ARNHEIM, R. Intuição e Intelecto na Arte. Rio de Janeiro: Martins Fontes, 1989.

BERGSON, H. A Percepção da Mudança. In: BERGSON, H. O Pensamento e o Movente: ensaios e conferências. São Paulo: Martins Fontes, 2006a. p.149-182. Texto original publicado em 1911.

BERGSON, H. Introdução. In: BERGSON, H. O Pensamento e o Movente: ensaios e conferências. São Paulo: Martins Fontes, 2006b. p.3-102. Texto original publicado em 1934.

CABRAL, M.C. Encontros que nos Movem: a leitura como experiência inventiva. 2006. Tese (Doutorado) Programa de Pós-Graduação em Psicologia, Universidade Federal do Rio de Janeiro, 2006, Rio de Janeiro, BR-RJ.

CANDLIN, F. Blindness, art and exclusion in museums and galleries. International Journal of Art and Design Education, New York, v. 22, n. 1, p. 100-110, 2003.

CANDLIN, F. Don't touch! Hands off! Art, blindness and conservation of expertise. Body \& Society, London, v. 10, n. 1, p.71-90, 2004.

CARIJÓ, F.; ALMEIDA, M.C.; KASTRUP, V. Por uma Estética Tátil: sobre a adaptação de obras de artes plásticas para deficientes visuais. Fractal: Revista de Psicologia, Niterói, v. 22, 2010, p. 85-100.

DELEUZE, G. Francis Bacon: logique de la sensation. Paris: Éd. de la Différence, 1981. 2 v.

DELEUZE, G. L'Abécédaire de Gilles Deleuze. Entrevistas com Claire Parnet. Realização de P.-A. Boutang. Paris : Éd. Montparnasse/Liberation, [1997?].

DEPRAZ, N.; VARELA, F. VERMERSCH, P. On becoming aware: a pragmatic of experiencing. Philadelphia: Benjamin Publ., 2003.

DEPRAZ, N.; VARELA, F. VERMERSCH, P. A Redução à Prova da Experiência. Tradução de André do Eirado e Virgínia Kastrup. Arquivos Brasileiros de Psicologia, Rio de Janeiro, v. 58, n. 1, 2006. Disponível em: <http:// www.psicologia.ufrj.br/abp/> Acesso em: jan. 2007.

DEWEY, J. A Arte Como Experiência. Traduzido para o português por Murilo Otávio Rodrigues Paes Leme. São Paulo: Abril Cultural, 1980. (Os Pensadores) Texto original publicado em 1950.

FERRAZ, G.C. A Percepção em Experimentação: uma dimensão política da experiência com a arte. 2010. Tese (doutorado) - Programa de Pós-Graduação em Psicologia, Universidade Federal do Rio de Janeiro, 2010, Rio de Janeiro, BR-RJ.

FONSECA, C. Projeto Oficina de Cerâmica Para Reabilitação de Portadores de Deficiência Visual do Instituto Benjamin Constant. Revista Benjamin Constant, Rio de Janeiro, ano 11, n. 30, p.24-25, 2005.

GIBSON, J.J. Observations on active touch. Psychological Review, Washington, v. 69, p. 477-490, 1962.

HATWELL, Y.; STRERI, A.; GENTAZ, E. (Org.). Toucher pour connaître: Psychologie cognitive de la perception tactile manuelle. Paris: Presses Universitaires de France, 2000.

KASTRUP, V. Cartografias Literárias. Revista do Departamento de Psicologia da UFF, Niterói, v. 14, n. 2,p .7594, 2002.

KASTRUP, V. O Devir-Consciente em Rodas de Poesia. Revista do Departamento de Psicologia da UFF, Niterói, v. 17, n. 2 , p. $45-60,2003$

KASTRUP, V. O Aprendizado da Atenção na Cognição Inventiva. Psicologia \& Sociedade, Belo Horizonte, v. 16, n. 3, p. 7-16, 2004. 
KASTRUP, V. Atenção e Auto-Produção nas Práticas de Si: deslocando a noção de auto-estima. In: COLÓQUIO FRANCO-BRASILEIRO DE FILOSOFIA DA EDUCAÇÃO: FOUCAULT 80 ANOS, 3.,2006, Rio de Janeiro. Anais. Rio de Janeiro: UERJ, 2006. 1 CD-ROM.

KASTRUP, V. A Invenção de Si e do Mundo: uma introdução do tempo e do coletivo no estudo da cognição. Belo Horizonte: Autêntica, 2007a.

KASTRUP, V. A Invenção na Ponta dos Dedos: a reversão da atenção em pessoas com deficiência visual. Psicologia em Revista, Belo Horizonte, v. 13, n. 1, p. 69-90, 2007b.

KASTRUP, V. O Lado de Dentro da Experiência: atenção a si mesmo e produção de subjetividade numa oficina de cerâmica para pessoas com deficiência visual adquirida. Psicologia: ciência e profissão, Brasília, v. 28, n. 1 , p. $186-199,2008$.

KASTRUP, V. Atualizando Virtualidades: construindo a articulação entre arte e deficiência visual. In: MORAES, Márcia; KASTRUP, V. (Org.). Exercícios de Ver e não Ver: arte e pesquisa com pessoas com deficiência visual. Rio de Janeiro: NAU, 2010. P. 52-73.

KASTRUP, V.; TEDESCO, S.; PASSOS, E. Políticas da Cognição. Porto Alegre: Sulina, 2008.

REVESZ, G. The psychology and art of the blind. Londres: Longmans Green, 1950.

SACKS, O. Um Antropólogo em Marte: sete histórias paradoxais. São Paulo: Cia das Letras, 1995.

VARELA, F. Conhecer: introdução à Ciência Cognitiva. Lisboa: Instituto Piaget, 1994.

VYGOTSKI, L. Fundamentos de defectología. In: VYGOTSKI, L. Obras escogidas, Madrid: Visor, 1997. V. 5. Texto original publicado em 1929

Recebido em março de 2010

Aprovado para publicação em junho de 2010

\section{Virgínia Kastrup}

Psicóloga pela Universidade Federal do Rio de Janeiro (1979), Mestrado em Psicologia pela Universidade Federal do Rio de Janeiro (1984), Doutorado em Psicologia Clínica pela Pontifícia Universidade Católica de São Paulo (1997) e Pós-Doutorado no CNRS, Paris (2002). Professora Associada da Universidade Federal do Rio de Janeiro-RJ/Brasil.

Email: virginia.kastrup@gmail.com 